\title{
List of metres
}

Canto 1 Śārdūlawikrīịita (Zoetmulder 1974:462)

$---|\sim-| \sim-\sim|\sim-|--\sim|--\sim|=$

Canto 2 Wirat Tĕbu Sol etc. (Zoetmulder 1974:466)

$\sim-\sim|\sim-| \sim-\sim \sim|\sim-| \sim-\cdots|-| \sim$

Canto 3 Jagaddhita etc. (Zoetmulder 1974:467)

$---|\sim-| \sim-\sim|\sim-| \sim|\sim|--\mid \sim$

Canto 4 Basantatilaka (Zoetmulder 1974:458)

$--\sim|-\sim-v| \sim-v|\sim-\sim|-=$

Canto 5 Śikhariṇ̄̄ (Zoetmulder 1974:460)

$\sim--|---| \sim-\cdots-|-\cdots| \sim$

Canto 6 Girisa (Zoetmulder 1974:459)

$\sim-\cdots---|---| \sim \mid=$

Canto 7 Sragdharā (Zoetmulder 1974:465)

$---|---|-\sim|\sim-c|--|---| \sim-\simeq$

Canto 8 Praharṣiṇī (Zoetmulder 1974:457)

$---|\sim----|--\mid=$ 
Canto 9 Suwadanā (Zoetmulder 1974:464)

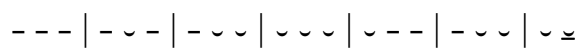

Canto 10 Mredukomala (Zoetmulder 1974:461)

$---|\sim-| \sim-\sim|\sim-| \sim-\sim \mid \sim=$

Canto 11 Toțaka (Zoetmulder 1974:455)

$\sim-|\sim-| \cup-\mid \cup=$

Canto 12 Rajan̄̄ (Zoetmulder 1974:460)

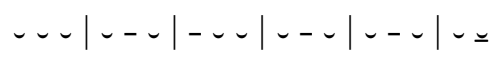

Canto 13 Wangśastha / Indrawangśa (in irregular alternation) (Zoetmulder 1974:456)

$--\sim|--\sim| \sim-\sim \mid-\sim=$

Canto 14 Kṛti (Zoetmulder 1974:463)

$\sim-|\sim-\sim| \sim-|\sim-| \sim-1--\mid \sim$

Canto 15 Kusumawilasita (Zoetmulder 1974:464)

$-\cdots|-\cdots| \sim-\cdots|\sim-\cdots|-\cdots$

Canto 16 Turidagati? (Zoetmulder 1974:465)

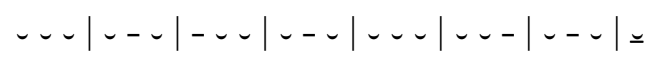

Canto 17 Praharșinī (as above)

Canto 18 Mṛdukomala (as above)

Canto 19 Mṛtatodaka (Zoetmulder 1974:454)

$---|\cup-| \sim \mid \sim=$ 
Canto 20 Jaloddhatagati (Zoetmulder 1974:455)

$--\sim|\sim-|--\sim \mid \sim=$

Canto 21 Basantatilaka (as above)

Canto 22 Sragdharā (as above)

Canto 23 Kilayu Anẹḍĕng (Zoetmulder 1974:465)

$-\cdots|\sim-\sim-| \sim-\sim|\sim-| \sim \sim|\sim|=$

Canto 24 Puṣpasañcaya (Zoetmulder 1974:466)

$-\cdots|-\cdots|-\cdots|-\cdots|-\cdots|-\cdots|-\cdots \mid-$

Canto 25 Śārdūlawikrīẹita (as above)

Canto 26 Dạ̣ḍasagala (Zoetmulder 1974:469)

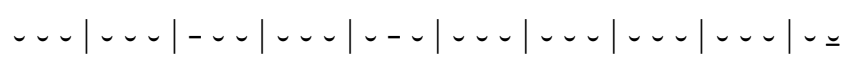

Canto 27 Jagaddhita (as above)

Canto 28 Rucirā (Zoetmulder 1974:457)

$\sim-\sim|-\sim| \sim-|\sim-\sim|=$

Canto 29 Nawaharșa (Zoetmulder 1974:462)

$\sim-|\sim-| \sim-\cdots|-\cdots|-\cdots \mid=$

Canto $30 \mathrm{Krnti}$ (as above)

Canto 31 Jagaddhita (as above)

Canto 32 Kilayu Aněḍĕng (as above)

Canto 33 Wirat Tĕbu Sol (as above)

Canto 34 Śikhariṇ̄ (as above) 
Canto 35 Jagaddhita (as above)

Canto 36 Mṛāngśa (Zoetmulder 1974:462)

$---|\sim-| \sim-\sim|\cdots-| \sim|\sim \sim|=$ 